\title{
Electrochemical immunosensor for the analysis of the breast cancer biomarker HER2 ECD
}

\author{
Raquel C.B. Marques, Subramanian Viswanathan, Henri P.A. Nouws, \\ Cristina Delerue-Matos, M. Begoña González-García
}

\begin{abstract}
A B S T R A C T
Human epidermal growth factor receptor 2 (HER2) is a breast cancer biomarker that plays a major role in promoting breast cancer cell proliferation and malignant growth. The extracellular domain (ECD) of HER2 can be shed into the blood stream and its concentration is measurable in the serum fraction of blood. In this work an electrochemical immunosensor for the analysis of HER2 ECD in human serum samples was developed. To achieve this goal a screen-printed carbon electrode, modified with gold nanoparticles, was used as transducer surface. A sandwich immunoassay, using two monoclonal antibodies, was employed and the detection of the antibody-antigen interaction was performed through the analysis of an enzymatic reaction product by linear sweep voltammetry. Using the optimized experimental conditions the calibration curve ( $i_{p}$ vs. $\log [$ HER2 ECD]) was established between 15 and $100 \mathrm{ng} / \mathrm{mL}$ and a limit of detection (LOD) of $4.4 \mathrm{ng} / \mathrm{mL}$ was achieved. These results indicate that the developed immunosensor could be a promising tool in breast cancer diagnostics, patient follow-up and monitoring of metastatic breast cancer since it allows quantification in a useful concentration range and has an LOD below the established cut-off value $(15 \mathrm{ng} / \mathrm{mL})$.
\end{abstract}

Keywords:

Breast cancer

HER2 ECD

Electrochemical immunosensor

Gold nanoparticles

Screen-printed carbon electrode

\section{Introduction}

Based on data published by the World Health Organization, in 2008 breast cancer was the most frequent cause of cancer death in women in both developing and developed regions. Incidence rates are high in developed regions of the world (except Japan) and low in most of the developing regions [1]. The higher incidence of breast cancer in developed countries has been tempered by reductions in mortality, largely attributable to mammographic screening programs and advances in adjuvant therapy [2]. However, mammography screening has moderate sensitivity and specificity and a low positive-predictive value in younger women. Therefore, research has been conducted to identify the critical biochemical changes in cancer and has led to advances in its detection and treatment [3]. The detection of tumor markers has a major importance for the diagnosis of the onset of breast cancer [4]. Tumor markers are substances that can be found in the body when cancer is present $[5,6]$. The biomarkers found in biological fluids, blood in particular, apparently hold the best promise for the development of screening assays [4]. A simple blood test that could detect these cancers in their earliest stages could prevent the deaths of millions of people and reduce the suffering of patients and their families and the cost to society. The amount of suggested biomarkers of breast cancer is ever-increasing, but many of them are without clinical value. The established biomarkers include tissue markers, such as estrogen and progesterone receptors and the human epidermal growth factor receptor 2 (HER2), and circulating markers, such as carcinoembryonic antigen (CEA) and cancer antigen 15-3 (CA 15-3). Circulating tumor cells are emerging biomarkers that have potential to become clinically useful $[2,7]$.

Regarding HER2, this receptor plays a major role in promoting breast cancer cell proliferation and malignant growth [7]. The HER2 gene expresses a transmembrane protein that is overexpressed in approximately $15-30 \%$ of breast cancers [8-12]. Breast cancers associated with HER2 over-expression have an accelerated growth and recurrence rate, and are associated with decreased overall patient survival [12]. HER2 is a $185 \mathrm{kDa}$ protein and has three domains: an extracellular domain (ECD), a transmembrane region, and an intracellular tyrosine kinase domain [10-12]. As many other membrane-anchored proteins, HER2 can release its ECD into the circulation through a proteolytic 
mechanism [10]. The concentration of HER2 ECD is measurable in the serum fraction of blood and is therefore a potential and clinically relevant marker for breast cancer [10]. The serum test, which can be included in routine blood analysis, is noninvasive and avoids the use of tissue (obtained by biopsy) which is necessary for the established diagnostic methods (immunohistochemistry (IHC) and fluorescent in situ hybridization (FISH)) for the assessment of HER2 status. Furthermore, the IHC and FISH methods only provide semi-qualitative results, separating patients into HER2-positive and HER2-negative groups [13], whereas a serum test provides quantitative results. An elevated HER2 ECD serum level, which is more frequently observed in metastatic breast cancer, is defined as $\geq 15 \mathrm{ng} / \mathrm{mL}$ and was detected by a Food and Drug Administration (FDA)-approved enzyme-linked immunosorbent assay (ELISA) in up to $45 \%$ of metastasized breast cancer patients $[8,12]$. Although the currently approved cut-off value is $15 \mathrm{ng} / \mathrm{mL}$, moderate increase $(50 \mathrm{ng} / \mathrm{mL})$ has also been described in the absence of cancer [10] and other cut-off values have been suggested [12]. The major advantage of a HER2 ECD serum test, besides its diagnostic value, is the possibility of patient follow-up and the monitoring of (metastatic) breast cancer, which is of critical importance in the choice of the HER2-targeted therapy. IHC and FISH are not commonly used for this purpose because of the location of the metastases and the costs of biopsies.

Serum HER2 ECD concentrations are mostly assessed by ELISAbased methods [12]. However, their lack of sensitivity and selectivity and high detection limits highlights the need for ultrasensitive immunological tests [12]. To overcome some of these problems, electrochemical immunosensors could be adequate alternatives because of their high selectivity and sensitivity which allows early detection of many diseases. The instrumentation needed to operate and analyze the results obtained by these biosensors has been reduced to pocket-size dimensions, which make them ideal for the incorporating in point-of-care devices.

To date two electrochemical immunosensing methods for the analysis of HER2 have been published [14,15]. Mucelli et al. [14] used nanoelectrode ensembles as the transducer and a sandwich immunoassay for the detection of HER2 in diluted cell lysates and tumor lysates. The lowest concentration they analyzed was $40 \mathrm{ng} /$ mL. Al-Khafaji et al. [15] applied antibody-functionalized magnetic beads in combination with a screen-printed carbon electrode. The detection limit of the used sandwich immunoassay was $6 \mathrm{ng} / \mathrm{mL}$.

In the present work a novel electrochemical immunosensor for the quantification of HER2 ECD in serum was developed by using a gold nanoparticle-modified screen-printed carbon electrode as transducer. Monoclonal anti-human-HER2 antibodies were immobilized on the transducer surface and after incubation with a HER2 ECD-containing sample biotinylated monoclonal anti-human-HER2 detection antibodies were added. A streptavidin-alkaline phosphatase conjugate was used to label the detection antibody. The detection of the antibody-antigen interaction was possible by using an enzymatic substrate (3-indoxyl phosphate, 3-IP) and silver ions. In the enzymatic reaction silver ions are reduced to metallic silver which can be analyzed by anodic stripping using linear sweep voltammetry.

\section{Materials and methods}

\subsection{Materials and apparatus}

All electrochemical procedures were performed using a potentiostat/galvanostat (Autolab PGSTAT101, Metrohm Autolab). The Autolab system was controlled by the NOVA software package (v.1.9; Metrohm Autolab). Single-use screen-printed carbon electrodes (SPCE, DRP-110) and a specific connector (DRP-CAC) to interface the SPCE and the potentiostat/galvanostat were supplied by DropSens. The SPCEs incorporate a conventional three-electrode configuration, printed on ceramic substrates $(3.4 \times 1.0 \mathrm{~cm})$. Both the working- (disk-shaped $4 \mathrm{~mm}$ diameter) and counter electrodes are made of carbon inks, whereas the pseudoreference electrode and the electric contacts are made of silver. A ring-shaped layer printed around the working electrode constitutes the reservoir $(50 \mu \mathrm{L})$ of the electrochemical cell. SEM images were obtained at the "Centro de Materiais da Universidade do Porto (CEMUP)" using FEI QUANTA 400 FEG / EDAX Pegasus X4M equipment.

\subsection{Reagents}

For the immunoassay an anti-human-HER2 ECD rabbit monoclonal capture antibody (Ab-capture), a recombinant HER2 ECD protein (antigen), and an anti-human-HER2 ECD mouse monoclonal biotinylated detection antibody (Ab-detection) were used (Sino Biological Inc.).

Tetrachloroauric(III) acid was obtained from Merck. Tris(hydroxymethyl)aminoethane, (Tris), streptavidin-alkaline phosphatase from Streptomyces avidinii (S-AP), 3-indoxyl phosphate disodium salt, $\beta$ casein from bovine milk, bovine serum albumin (BSA), human serum (from male $\mathrm{AB}$ clotted whole blood), magnesium nitrate hexahydrate, and nitric acid ( $\geq 65 \%$ ) were purchased from Sigma-Aldrich. Silver nitrate was supplied by Alfa Aesar.

Ultra-pure water (resistivity $=18.2 \mathrm{M} \Omega . \mathrm{cm}$ ) obtained from a Millipore water purification system (Simplicity 185) was used throughout the study.

Two Tris- $\mathrm{HNO}_{3}$ buffers were used in the experiments: Buffer 1: $0.1 \mathrm{M}(\mathrm{pH} 7.2)$ and Buffer 2: $0.1 \mathrm{M}(\mathrm{pH} 9.8)+20 \mathrm{mM} \mathrm{MgNO}_{3}$. The solutions of the reagents used in the immunoassay were prepared
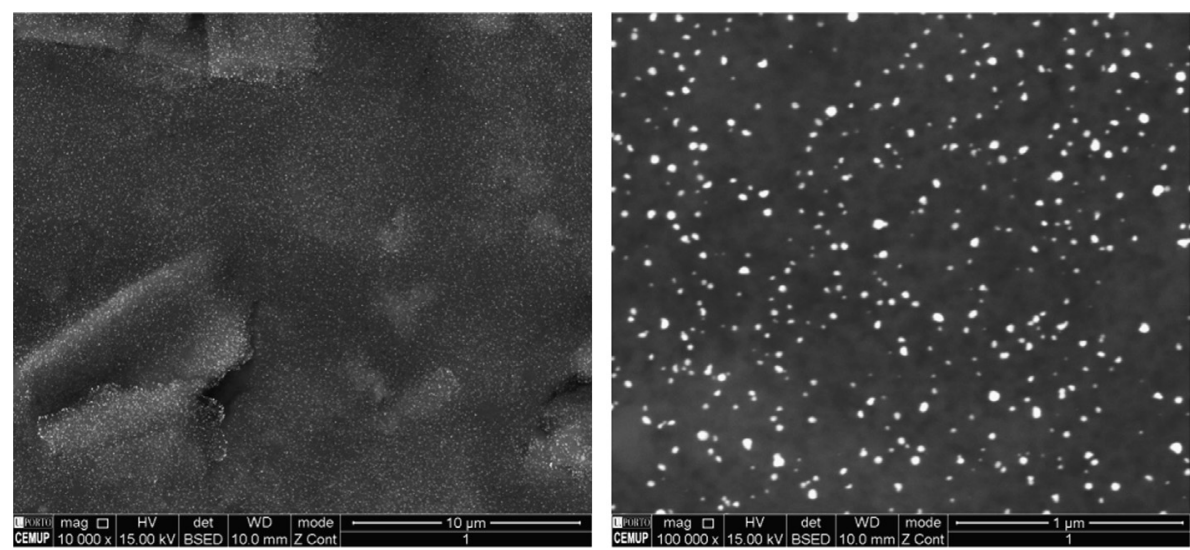

Fig. 1. SEM images of the screen-printed carbon electrode modified with gold nanoparticles. 
in Buffer 1, except for the 3-IP/Ag ${ }^{+}$solution which was prepared in Buffer 2.

\subsection{Electrode surface modification with gold nanoparticles}

The modification of the SPCEs' surfaces with gold nanoparticles (AuNPs) was achieved through electrodeposition of gold from $40 \mu \mathrm{L}$ of a $0.1 \mathrm{mM}\left[\mathrm{AuCl}_{4}\right]^{-}$(in $0.1 \mathrm{M} \mathrm{HCl}$ ) solution. The AuNPs were deposited by applying a constant current $(-100 \mu \mathrm{A})$ for $240 \mathrm{~s}$, followed by the application of a constant potential $(+0.1 \mathrm{~V})$ for $120 \mathrm{~s}$ [16]. The size of the AuNPs obtained using this procedure is $32 \pm 10 \mathrm{~nm}$ (Fig. 1).

\subsection{Electrochemical immunoassay}

After the nanostructuration of the SPCE, the biosensing phase of the immunosensor was constructed as follows: (i) immobilization through adsorption by placing $10 \mu \mathrm{L}$ of a capture antibody solution on the transducer's surface (overnight incubation); (ii) surface blocking with $40 \mu \mathrm{L}$ of a $\beta$-casein solution (2\%) (30 min). After both steps the SPCE was washed with Buffer 1 and dried.

The immunoassay (Fig. 2) consisted of the following steps: (i) incubation with the antigen (HER2 ECD) $(40 \mu \mathrm{L} ; 1 \mathrm{~h})$; (ii) addition of $40 \mu \mathrm{L}$ of a biotinylated detection antibody solution (1 h); (iii) addition of $40 \mu \mathrm{L}$ of an S-AP solution (1 h); (iv) addition of $40 \mu \mathrm{L}$ of a solution containing the enzymatic substrate (3-IP) $(1.0 \mathrm{mM})$ and silver ions $(0.40 \mathrm{mM})(20 \mathrm{~min})(\mathrm{v})$ detection of the analytical signal by linear sweep voltammetry (potential scan: -0.03 to $+0.4 \mathrm{~V}$; scan rate: $0.05 \mathrm{~V} / \mathrm{s}$ ). This signal was obtained through the anodic stripping of the enzymatically generated metallic silver [17]. After steps (i) and (ii) the SPCE was washed with Buffer 1 and dried. After step (iii) the SPCE washed with Buffer 2 and dried.

\section{Results and discussion}

\subsection{Optimization of the electrochemical immunoassay}

In the optimization of the S-AP concentration, four different concentrations were used: $1 \times 10^{-10} ; 2 \times 10^{-10} ; 5 \times 10^{-10}$ and
$1 \times 10^{-9} \mathrm{M}$. The obtained peak current intensities $\left(i_{p} ; n=3\right)$ are presented in Fig. 3.

As can be observed in Fig. 3 the $i_{p}$ increases with the increase of S-AP concentration for both the blank assays as well as the assays in which the antigen was used. Furthermore, the precision of the results decreases when the S-AP concentration is increased. Therefore, an S-AP concentration of $2 \times 10^{-10} \mathrm{M}$ was chosen for the subsequent studies.

In order to reduce the analysis time the combination of several steps of the immunoassay was studied by pre-incubating the reagents before their placement on the SPCE. The tested alternatives were: (1) mixture of HER2 ECD with the detection antibody; (2) mixture of the detection antibody with S-AP; and (3) mixture of HER2 ECD with the detection antibody and S-AP.

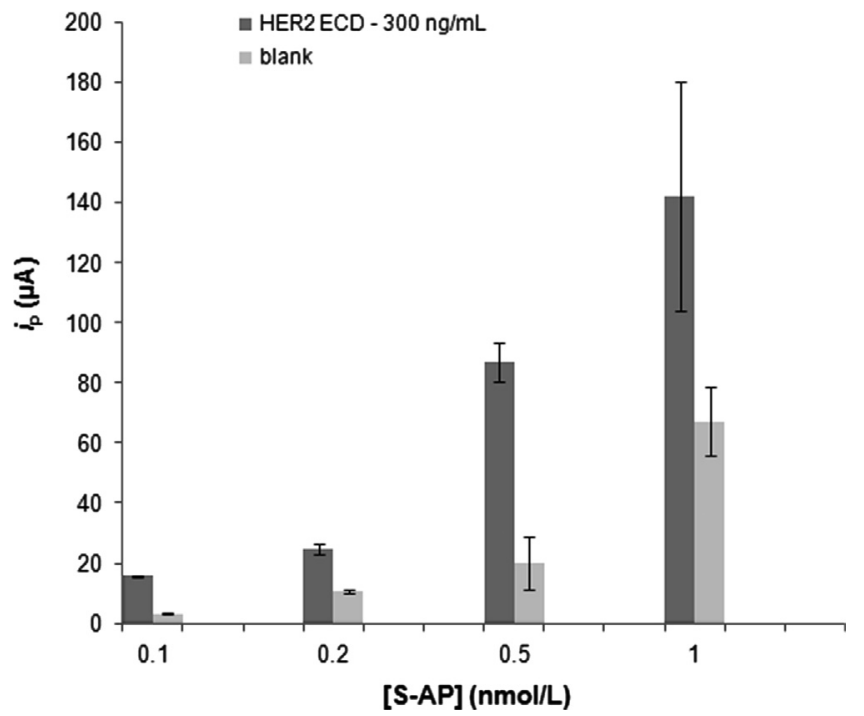

Fig. 3. Obtained $i_{p}(n=3)$ by linear sweep voltammetry for different S-AP concentrations $\left(1 \times 10^{-10} ; 2 \times 10^{-10} ; 5 \times 10^{-10}\right.$ and $\left.1 \times 10^{-9} \mathrm{M}\right)$. (Ab-capture $(50 \mu \mathrm{g} / \mathrm{mL})$, casein (2\%), HER2 ECD (0 (blank) and $300 \mathrm{ng} / \mathrm{mL})$, Ab-detection $(5 \mu \mathrm{g} /$ $\mathrm{mL}), 3-\mathrm{IP}(1.0 \mathrm{mM})$ and $\left.\mathrm{Ag}^{+}(0.40 \mathrm{mM})\right)$.

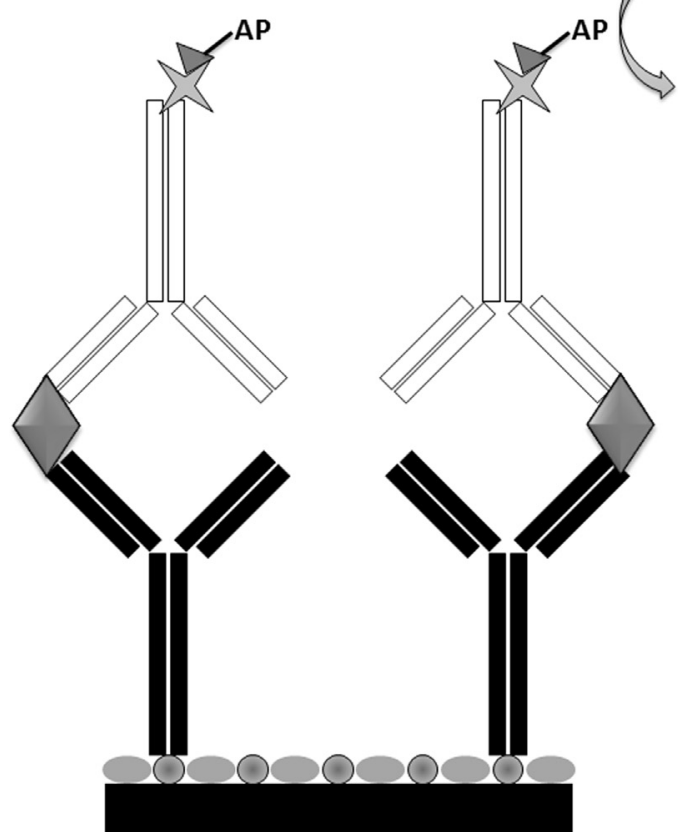

3-IP/ $\mathrm{Ag}^{+}$

$\mathrm{Ag}^{0}{ }_{(\mathrm{s})}$

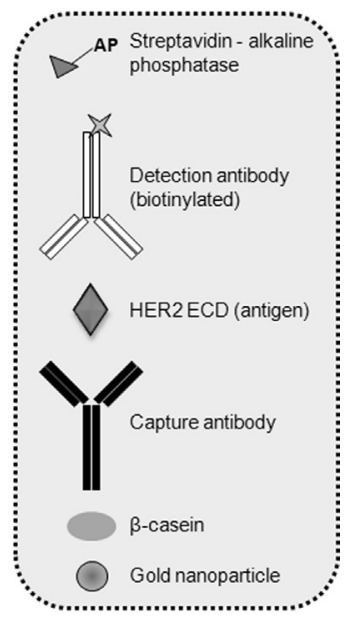

Fig. 2. Schematic representation of the immunoassay. 
Because of the relatively high signals obtained in the blank assays, which impedes the detection of low HER2 ECD concentrations, BSA (final concentration: 0.5\%) was added to the mixtures to reduce non-specific adsorption.

The alternatives (2) and (3) mentioned above were unsuccessful because no stripping current $\left(i_{p}=0\right)$ was observed. The obtained peak current intensities $\left(i_{p} ; n=3\right.$ ) for a normal (no previous mixing of reagents, but addition of BSA (0.5\%) to the HER2 ECD and Ab-detection solutions) and the alternative (1) assay are presented in Fig. 4.

As can be seen in Fig. 4 the pre-incubation of the antigen with the detection antibody resulted in a decrease of the blank signal and an increase of the analyte/blank signal ratio when compared

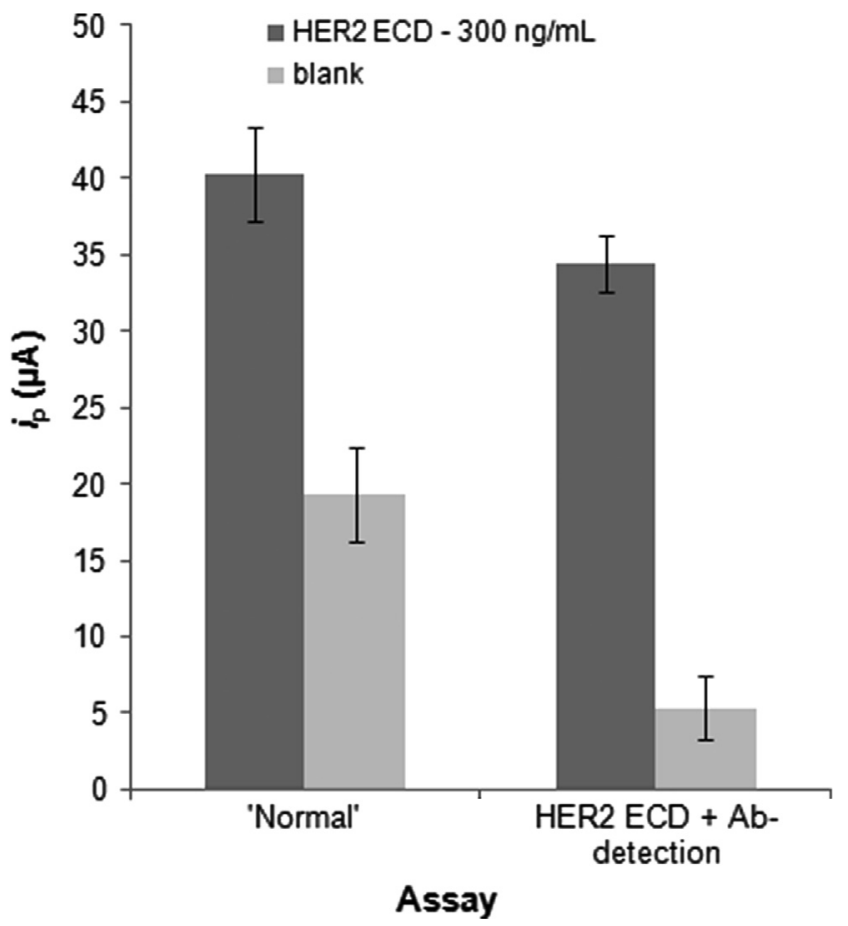

Fig. 4. Obtained $i_{p}(n=3)$ by linear sweep voltammetry for different assay strategies. (Ab-capture $(50 \mu \mathrm{g} / \mathrm{mL}$ ), casein (2\%), HER2 ECD (0 (blank) and $300 \mathrm{ng} / \mathrm{mL}), \mathrm{Ab}$ detection $(5 \mu \mathrm{g} / \mathrm{mL})$, BSA $(0.5 \%)$, S-AP $\left(2 \times 10^{-10} \mathrm{M}\right)$, 3-IP $(1.0 \mathrm{mM})$ and $\mathrm{Ag}^{+}$ $(0.40 \mathrm{mM})$. to the 'normal' assay. This can be explained by the additional washing step in the 'normal' assay which reduces the surface blockage and increases non-specific adsorptions. The use of the pre-incubation step (which is the combination of steps (i) and (ii) of the immunoassay (see Section 2.4)) leads to a 1-h decrease of the assay time (total time: $2 \mathrm{~h} / 50 \mathrm{~min}$ ) and was therefore used in the subsequent studies. To evaluate the ideal incubation time of the HER ECD-Ab-detection mixture, assays were performed by mixing the reagents $5 \mathrm{~min}$ and $1 \mathrm{~h}$ before their placement on the SPCE. No significant differences between the $i_{p}$ values were obtained for both the blanks $\left(\Delta i_{p}=0.21 \mu \mathrm{A}\right)$ as well as the assays in which the antigen was used $\left(\Delta i_{p}=2.6 \mu \mathrm{A}\right)$. A 5-min preincubation time was selected for the next studies.

For the optimization of the Ab-capture and Ab-detection concentrations assays using the following conditions were performed: Ab-capture: 10, 25 and $50 \mu \mathrm{g} / \mathrm{mL}$, casein: $2 \%$, HER2 ECD: 0 (blank) and $150 \mathrm{ng} / \mathrm{mL}, \mathrm{Ab}$-detection: $0.1 ; 0.5$ and $1 \mu \mathrm{g} / \mathrm{mL}, \mathrm{BSA}$ : 0.5\%, S-AP: $2 \times 10^{-10} \mathrm{M}, 3-\mathrm{IP}: 1.0 \mathrm{mM}$ and $\mathrm{Ag}^{+}: 0.40 \mathrm{mM}$.

In the majority of the assays an increase of the $i_{p}$ was observed when the antibody concentrations were increased (Fig. 5). The highest $i_{p}$ was obtained when the Ab-capture and Ab-detection concentrations were $50 \mu \mathrm{g} / \mathrm{mL}$ and $1 \mu \mathrm{g} / \mathrm{mL}$, respectively. These concentrations were used for the analysis of HER2 ECD in human serum.

\subsection{Serum analysis}

To establish the calibration curve for the analysis of HER2 ECD in human serum, first the working range was evaluated by analyzing HER2 ECD (15 to $150 \mathrm{ng} / \mathrm{mL}$ ) in buffer solutions using the optimized electrochemical immunoassay. A linear relationship between $i_{p}$ and $\log \left[\right.$ HER2 ECD] $\left(i_{p}=(37.74 \pm 2.90) \log [\right.$ HER2 ECD $]-$ $(18.33 \pm 5.01), r=0.991, n=5)$ was established in the entire studied range. The same concentrations were used for the analysis of HER2 ECD in spiked human serum. In these experiments BSA was not added to the mixture of HER2 ECD and Ab-detection to avoid complete blockage of the transducer's surface. Typical voltammograms obtained in the analysis of the serum samples are presented in Fig. 6a. A clear difference was observed between the $i_{p}$ of the blank assay and the lowest antigen concentration $(15 \mathrm{ng} / \mathrm{mL})$, which corresponds to the established cut-off value. The linear range was established between 15 and $100 \mathrm{ng} / \mathrm{mL}$ HER2 ECD (Fig. 6b).

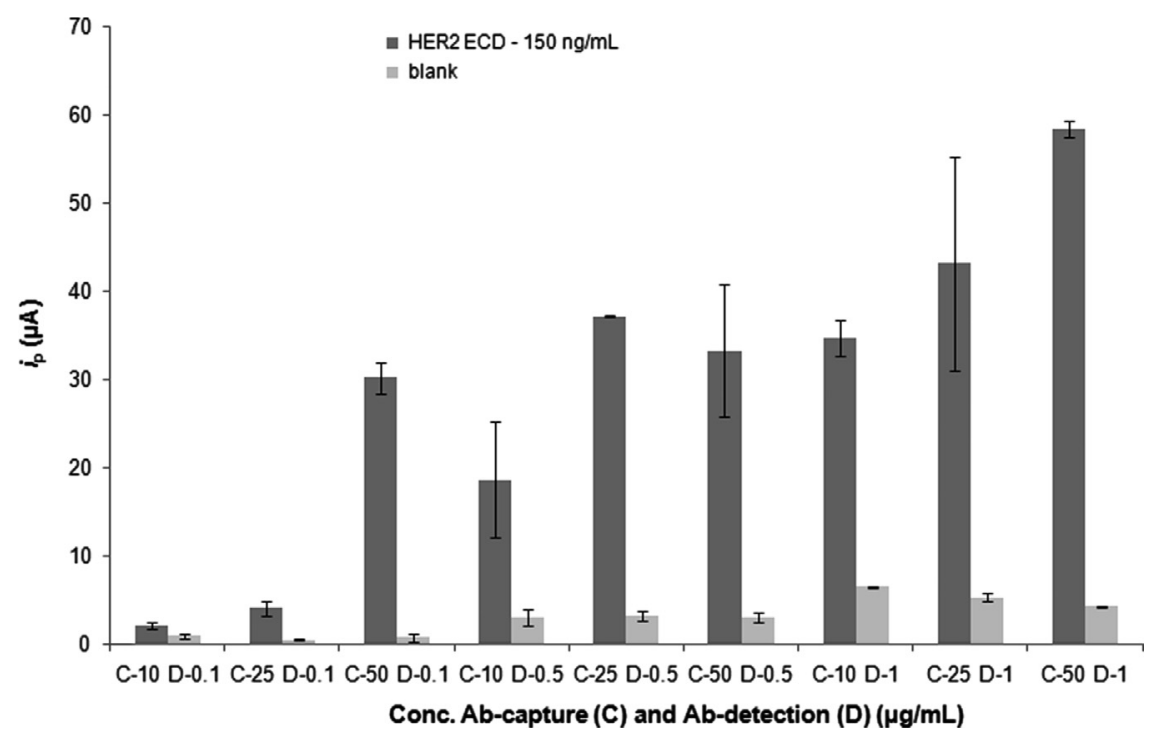

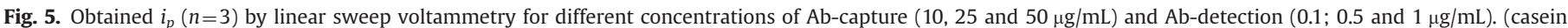
(2\%), HER2 ECD (0 (blank) and $\left.150 \mathrm{ng} / \mathrm{mL}), \mathrm{BSA}(0.5 \%), \mathrm{S}-\mathrm{AP}\left(2 \times 10^{-10} \mathrm{M}\right), 3-\mathrm{IP}(1.0 \mathrm{mM}) \mathrm{and} \mathrm{Ag}^{+}(0.40 \mathrm{mM})\right)$. 

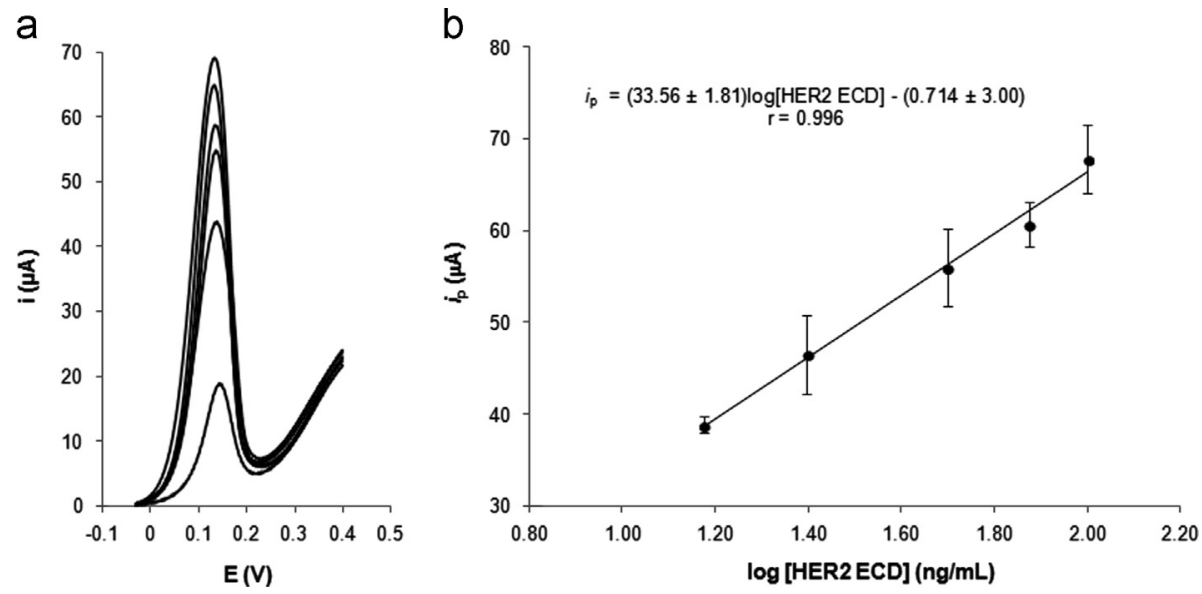

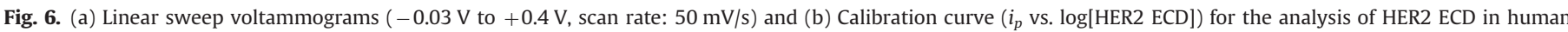

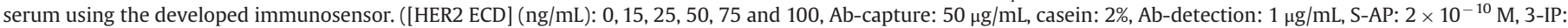
$1.0 \mathrm{mM}$ and $\mathrm{Ag}^{+}: 0.40 \mathrm{mM}$ ).

Table 1

Figures of merit of the developed electrochemical immunoassay for the analysis of HER2 ECD in human serum samples.

\begin{tabular}{ll}
\hline Figure of merit & \\
\hline Concentration interval $(\mathrm{ng} / \mathrm{mL})$ & $15-100$ \\
Correlation coefficient $(r)$ & 0.996 \\
Slope $(\mathrm{m})$ & 33.56 \\
Standard deviation of the slope $\left(S_{m}\right)$ & 1.81 \\
Intercept $(a)$ & -0.714 \\
Standard deviation of the intercept $\left(S_{a}\right)$ & 3.00 \\
Standard deviation of the linear regression $\left(S_{y / x}\right)$ & 1.23 \\
Standard deviation of the method $\left(S_{x 0}\right)$ & 0.037 \\
Coefficient of variation of the method $\left(V_{x 0}\right)(\%)$ & 2.2 \\
Limit of detection $(\mathrm{LOD})(\mathrm{ng} / \mathrm{mL})$ & 4.4 \\
\hline
\end{tabular}

The slope of the calibration curve for the serum analysis was slightly lower than the slope obtained in the analysis of aqueous solutions, so the influence of the serum matrix is reduced. In Table 1 several figures of merit $[18,19]$ for the developed electrochemical immunoassay are indicated. The limit of detection was calculated using the average blank signal plus three times the standard deviation.

Based on the data presented in Table 1 it can be concluded that the developed immunosensor presents a useful concentration interval because it allows the quantification of the biomarker in a relatively wide concentration range, which could allow the evaluation of the patient's response to therapy. For high HER2 ECD concentrations (outside the calibration interval) a simple dilution of the sample with buffer will be sufficient. The limit of detection for the analysis of HER2 ECD is well below the established cut-off value $(15 \mathrm{ng} / \mathrm{mL})$, which allows the early diagnosis of breast cancer associated with HER2 over-expression. The precision of the method is also adequate since $V_{x 0}<5 \%$ and the average CV for the spiked serum samples was $5.7 \%$.

In comparison with the published electrochemical immunoassay for serum HER2 ECD analysis [15], the analysis time of the developed immunosensor in this work was slightly longer ( $\pm 20 \mathrm{~min}$ ). However, in the previous study the linear calibration curve was established only between 0 and $15 \mathrm{ng} / \mathrm{mL}(n=4)$, the LOD was $6 \mathrm{ng} / \mathrm{mL}$ and the reproducibility for spiked serum samples in terms of CV was about $10 \%$. Therefore, the developed immunosensor presents better performance characteristics than the previously developed assay.

Currently two commercial and FDA-approved HER2 ECD serum tests, both based on immunological sandwich assays, are available: the Siemens Healthcare Diagnostics ADVIA Centaur ${ }^{\circledR}$ Serum HER- 2/neu test and the Oncogene Science ${ }^{\circledR}$ HER-2/neu ELISA (Wilex Inc.). The Siemens test is fully automated and presents a very short analysis time ( $<10 \mathrm{~min}$ ), a concentration range between 0.5 and $350 \mathrm{ng} / \mathrm{mL}$ and an LOD of $0.5 \mathrm{ng} / \mathrm{mL}$. The reported CV is between 3.2 and $5.7 \%$. The major drawback of this assay is the relatively costly equipment necessary for the assay performance, which is therefore not widely available. Here the Oncogene Science ${ }^{\circledR}$ HER$2 /$ neu ELISA presents an alternative, but presents a narrower concentration range $(1.5-35 \mathrm{ng} / \mathrm{mL})$, higher LOD $(1.5 \mathrm{ng} / \mathrm{mL})$ and CV (1-17.7\%), and a much longer analysis time ( $>5 \mathrm{~h} / 15 \mathrm{~min})$. In general, the performance characteristics of the immunosensor developed in this work are similar to those of the commercial tests. Therefore, the developed immunosensor could be a promising tool in breast cancer diagnostics, patient follow-up and monitoring of metastatic breast cancer.

\section{Conclusions}

An electrochemical immunosensor for the analysis of HER2 ECD in human serum was developed by using a gold nanoparticlemodified screen-printed carbon electrode as transducer and a sandwich immunoassay. The optimized analysis time was $2 \mathrm{~h} /$ $50 \mathrm{~min}$. The calibration curve ( $i_{p}$ vs $\log [\mathrm{HER} 2 \mathrm{ECD}]$ ) was established between 15 and $100 \mathrm{ng} / \mathrm{mL}$ and a limit of detection of $4.4 \mathrm{ng} / \mathrm{mL}$ was achieved. Like this, the developed electrochemical immunosensor could be useful in the diagnostic and follow-up of (metastatic) breast cancer patients. However, additional studies using blood samples from healthy individuals and cancer patients should be conducted to evaluate the sensor's utility and validate its performance in clinical settings.

\section{Acknowledgements}

This work received financial support from the European Union (FEDER funds through COMPETE) and National Funds (FCT, Fundação para a Ciência e a Tecnologia) through projects PTDC/SAUENB/114786/2009 and Pest-C/EQB/LA0006/2013.

\section{References}

[1] World Health Organization, International Agency for Research on Cancer, GLOBOCAN 2008, 〈http://globocan.iarc.fr〉, (accessed 19 Sept. 2013).

[2] N. Patani, L.-A. Martin, M. Dowsett, Int. J. Cancer 133 (2013) 1-13.

[3] K.D. Cole, H.-J. He, L. Wang, Proteomics Clin. Appl. 7 (2013) 17-29. 
[4] V.V. Levenson, Biochim. Biophys. Acta 1770 (2007) 847-856.

[5] J.L. Jesneck, S. Mukherjee, Z. Yurkovetsky, M. Clyde, J.R. Marks, A.E. Lokshin, J.Y. Lo, BMC Cancer 9 (2009) 164.

[6] N.L. Henry, D.F. Hayes, Oncology 6 (2012) 140-146.

[7] A. Nicolini, A. Carpi, G. Tarro, Front. Biosci. 11 (2006) 1818-1843.

[8] C.B. Moelans, R.A. de Weger, E. van der Wall, P.J. van Diest, Crit. Rev. Oncol Hematol. 80 (2011) 380-392.

[9] C. Gutierrez, R. Schiff, Arch. Pathol. Lab. Med. 135 (2011) 55-62.

[10] C. Tsé, A.-S. Gauchez, W. Jacot, P.-J. Lamy, Cancer Treat. Rev. 38 (2012) 133-142.

[11] L.J. Tafe, G.J. Tsongalis, Clin. Chem. Lab. Med. 50 (2012) 23-30.

[12] L. Lam, N. McAndrew, M. Yee, T. Fu, J.C. Tchou, H. Zhang, Biochim. Biophys. Acta 1826 (2012) 199-208

[13] W.P. Carney, D. Bernhardt, B. Jasani, Cancer 5 (2013) 31-39.
[14] S.P. Mucelli, M. Zamuner, M. Tormen, G. Stanta, P. Ugo, Biosens. Bioelectron. 23 (2008) 1900-1903.

[15] Q.A.M. Al-Khafaji, M. Harris, S. Tombelli, S. Laschi, A.P.F. Turner, M. Mascini, G. Marrazza, Electroanalysis 24 (2012) 735-742.

[16] G. Martínez-Paredes, M.B. González-García, A. Costa-García, Electrochim. Acta 54 (2009) 4801-4808.

[17] P. Fanjul-Bolado, D. Hernández-Santos, M.B. González-García, A. Costa-García, Anal. Chem. 79 (2007) 5272-5277.

[18] International Organization for Standardization, Water Quality-Calibration and Evaluation of Analytical Methods and Estimation of Performance Characteristics [ISO 8466-1:1990], Geneva, 1990.

[19] J.N. Miller, J.C. Miller, Statistics and Chemometrics for Analytical Chemistry, sixth ed., Pearson Education Limited, Harlow, 2000. 